\title{
Influence of body posture on the association between postpartum depression and pain
}

\author{
Influência do tipo postural na associação entre depressão pós-parto e dor
}

Rita di Cássia de Oliveira Angelo, ${ }^{1}$ Denila Coelho da Silva, ${ }^{2}$ Carla Fonseca Zambaldi, ${ }^{3}$ Amaury Cantilino, ${ }^{4}$ Everton Botelho Sougey ${ }^{5}$

\begin{abstract}
Objective: To determine the association between postpartum depression (PPD), intensification of back pain and exacerbation of changes in postural alignment intrinsic to puerperium.

Methods: Eighty women at 2 to 30 weeks postpartum were included in the study according to the following criteria: literate mothers, gestation of 34 to 42 weeks, and healthy live-born infants. All mothers agreed to participate in the study. Depressive symptoms were measured using the Edinburgh Postnatal Depression Scale (EPDS). Pain was assessed using a visual analogue scale (VAS) and the Nordic Musculoskeletal Questionnaire (NMQ), and posture, using real time naturalistic observation.

Results: There was a statistically significant association between PPD and pain intensity $(p=0.002)$. The upper back was the most frequent pain site among depressed women, both before $(p=0.04)$ and after delivery $(p=0.01)$. There were no associations between PPD and type of posture $(p=0.328)$. However, pain intensity was greater among depressed women in the swayback group $(p<0.001)$.

Conclusion: The intensification of puerperal pain is closely associated with PPD. Our results suggest that back pain may be both a risk factor and a comorbidity of PPD among puerperal women and that pain and type of posture are interdependent.
\end{abstract}

Keywords: Depression, pain, posture, postpartum

\section{Resumo}

Objetivo: Verificar a associação entre depressão pós-parto (DPP), intensificação do quadro álgico na região posterior do tronco e exacerbação das alterações no alinhamento postural intrínsecas ao puerpério.

Métodos: Foram selecionadas 80 mulheres em pós-parto de 2 a 30 semanas, de acordo com os seguintes critérios: mães alfabetizadas; gestação entre 34 e 42 semanas; parição de bebê saudável e vivo. Todas as mães concordaram em participar da pesquisa. Os sintomas depressivos foram rastreados através da Escala de Depressão Pós-natal de Edimburgo (EDPE). A avaliação da dor ocorreu através de uma escala visual analógica (EVA) e do Questionário Nórdico de Sintomas Osteomusculares (QNSO). Para avaliação postural, empregou-se observação naturalística em tempo real.

Resultados: Foi verificada associação estatisticamente significativa entre DPP e maior intensidade de dor referida $(p=0,002)$. A região dorsal foi o sítio doloroso mais apontado pelas puérperas deprimidas, tanto no período pré-puerperal $(p=0,04)$, quanto no puerpério $(p=0,01)$. Não houve associação estatística entre DPP e tipo postural $(p=0,328)$. No entanto, a intensidade da dor foi maior entre as mulheres deprimidas no grupo com postura desleixada (swayback) $(p<0,001)$.

Conclusão: A intensificação do quadro álgico puerperal associa-se fortemente à DPP. Nas puérperas deste estudo, a dor na região dorsal aparentemente se comportou tanto como um fator de risco quanto como uma comorbidade de DPP. Admite-se que existe uma relação de interdependência entre dor e tipo postural. Descritores: Depressão, dor, postura, pós-parto

\footnotetext{
${ }^{1}$ PhD in Neuropsychiatry and Behavioral Sciences, Universidade Federal de Pernambuco (UFPE), Recife, PE, Brazil. Assistant professor, Department of Physical Therapy, Universidade de Pernambuco (UPE), Petrolina, PE, Brazil. ${ }^{2}$ Physical therapist, UPE, Petrolina, PE, Brazil. ${ }^{3}$ Psychiatrist. PhD in Neuropsychiatry and Behavioral Sciences, UFPE, Recife, PE, Brazil. ${ }^{4}$ PhD in Neuropsychiatry and Behavioral Sciences, UFPE, Recife, PE, Brazil. Adjunct professor, Department of Neuropsychiatry, UFPE, Recife, PE, Brazil. ${ }^{5} \mathrm{PhD}$ in Mental Health, Universidade Estadual de Campinas (UNICAMP), Campinas, SP, Brazil. Associate professor, Department of Neuropsychiatry, UFPE, Recife, PE, Brazil.

This study was carried out at Universidade Federal de Pernambuco (UFPE), Recife, PE, Brazil. This paper is part of the doctoral thesis entitled "Dor e alinhamento postural em puérperas deprimidas e não deprimidas" ("Pain and postural alignment in depressed and non-depressed puerperal women"), developed in 2013 as part of the Graduate Program in Neuropsychiatry and Behavioral Sciences of Universidade Federal de Pernambuco (UFPE), Recife, PE, Brazil.

Financial support: Programa de Fortalecimento Acadêmico da Universidade de Pernambuco (PFAUPE).

Submitted Jul 05 2013, accepted for publication Nov 20 2013. No conflicts of interest declared concerning the publication of this article.

Suggested citation: Angelo RCO, Silva DC, Zambaldi CF, Cantilino A, Sougey EB. Influence of body posture on the association between postpartum depression and pain. Trends Psychiatry Psychother. 2014;36(1):32-39. http://dx.doi.org/10.1590/2237-6089-2013-0029
} 


\section{Introduction}

Posture is determined by the capacity to maintain an adequate relation between body segments and the body as a whole. ${ }^{1}$ Biomechanical changes in body posture during pregnancy are adaptive responses to the anatomic and physiological changes inherent to this period of life. ${ }^{2}$ Almost all women seem to experience some musculoskeletal discomfort during pregnancy, and about 25\% have disabling symptoms. Moreover, some women develop musculoskeletal disorders after delivery due to hormone effects and the ergonomic stress of caring for a newborn..$^{3,4}$ The prevalence of back musculoskeletal discomfort during puerperium ranges from 16 to $61 \% .^{5-8}$

In addition to physical discomfort, emotional disorders may affect women during puerperium. ${ }^{9-12}$ Emotional health, directly associated with muscle and physiological functions, affects posture and the genesis of pain. ${ }^{13}$ The pregnancypuerperium cycle is a period of great incidence of mood disorders, particularly postpartum depression (PPD), which has a prevalence that ranges from 3.6 to $20 \%$ among adult women. ${ }^{10,11,14}$ PPD is a non-psychotic disorder characterized by a persistent mood disorder; loss of pleasure and interest in usual activities, eating disorders, sleepiness, psychomotor disorders and loss of concentration and self-esteem. ${ }^{12}$

As no form of mental life is independent from physical life, mental disorders are also physical. Therefore, mental disorders should not be understood separately from physical changes. ${ }^{15}$

Emotional disorders resulting from negative emotions affect musculoskeletal function and control and may play an important role in the genesis of pain. ${ }^{16}$ About two thirds of the patients with depression have a clinical condition with physical symptoms, such as lack of energy and generalized pain. ${ }^{17}$ In spite of that, few studies have studied the association between depressive disorders and poor posture alignment. A Brazilian study described posture changes associated with major depression in men and women and found that the most prevalent posture types were thoracic kyphosis and head forward. ${ }^{18}$

Physiotherapists who treat pain should be prepared to identify depressive symptoms as a comorbidity associated with posture changes and recurrent symptoms, signs of remission and recurrence that generate difficulties for treatment progression. ${ }^{7}$ This study evaluated the association between postpartum depression, back pain intensification and exacerbation of changes in posture alignment that are intrinsic to puerperium.

\section{Material and methods}

This cross-sectional analytical study was conducted in a Brazilian Unified Health System Unit, a reference service in prenatal care, delivery and birth in the Integrated Development Region (Região Integrada de Desenvolvimento, RDE) of Polo Petrolina, in the State of Pernambuco, and in Juazeiro, in the State of Bahia, both in Brazil, from July 2011 to June 2012. In accordance with Resolution no. 196/1996 of the Brazilian Health Council, this study was approved by the Ethics in Research Committee of Universidade de Pernambuco, Brazil, under no. CAAE 0072.0.097.000-11.

Initially, a pilot study with the same eligibility criteria was conducted to test applicability and adequacy of the study instruments and to estimate sample size. The first sample comprised 58 puerperal women, and PPD frequency was $29.3 \%$. The results of the Pearson test revealed a moderate $(r=0.37)$ and statistically significant ( $p=0.004)$ correlation between PPD and pain. The BioEstat software (Sociedade Civil Mamirauá, Tefé, Brazil, release 5.3, 2008) was used to calculate sample size, which, according to the correlation coefficient found in the pilot study, at a power of $80 \%$ and a level of significance of $5 \%$, was 60 women.

Inclusion criteria were: 18 years or older; two to 30 weeks postpartum; gestation of 34 to 42 weeks; capacity to speak and understand Portuguese; healthy live-born infant; agreement to participate in the study and signature of an informed consent term. Women were excluded if they had orthopedic diseases or spine or lower extremity deformities, history of psychoactive drug use or previous psychiatric treatment, and history of illicit drug use or sexual abuse.

First, all participants answered a semi-structured interview about sociodemographic data, factors associated with behavior and living habits, personal and family history, and sexual, reproductive, clinical, obstetric and neonatal history. Depressive symptoms were assessed using the Edinburgh Postnatal Depression Scale (EPDS), ${ }^{19}$ a self-report instrument with 10 questions scored 0 to 3 . The total number of possible points is 30 , and a value equal to or greater than 13 indicates the presence of depressive symptoms.

The Nordic Musculoskeletal Questionnaire (NMQ) was used to assess capacity to perceive pain in different body regions and limitations or difficulties in the performance of work or daily life activities. ${ }^{20}$ In this instrument, two specific questionnaires focus on the anatomic areas where musculoskeletal symptoms are more frequent. Questions asked about symptom duration at two time points: 12 months (pre-puerperal time) and 7 days (puerperal time) before the interview. Participants were also asked whether pain was disabling and if they had pain at the time of the interview. Pain intensity was evaluated using a visual analog scale (VAS) ${ }^{21}$ ranging from zero (no pain) to 10 (most intense pain imaginable). 
Reported pain intensity was classified using the VAS median value. Therefore, scores equal to or lower than five were classified as no or mild pain, whereas scores greater than five indicated moderate to intense pain.

For the visual evaluation of posture, the participants were standing on a $60-\mathrm{cm}$ base in the form of a cross and before a posture analysis grid set up on the wall. Their medial malleoli were placed towards the axis to form a support polygon. Visual findings was recorded for the anterior and posterior views and right and left lateral views and, for each change of position, the patients were told to turn around the longitudinal axis of their own body. At each change of position, the observer repositioned the patient's feet. Overall posture was assessed according to the criteria described by Kendall, McCreary and Provance. ${ }^{22}$ Postures were classified as neutral, flat back, lordotic, kypholordotic and swayback.

In the neutral posture, the head has no inclination or rotation and the spine has normal curves. The scapulae are connected in the upper part of the back. In the pelvis, the anterior superior iliac spines are on the same vertical plane as the pubic symphysis and at the same height as the posterior superior iliac spines. ${ }^{22}$

The flat back posture is characterized by forward head protrusion, slightly extended cervical spine, increased flexion of the upper part of the thoracic spine and straight lower part. The lower back is flattened, and the pelvis, inclined backwards. In lordosis, the head has a neutral position. The cervical and thoracic regions have normal curves. The lower back is hyperextended and the pelvis, inclined forward. In the kypholordotic posture, the head is forward and the spine is hyperextended. There is scapular abduction, and kyphosis is accentuated. Lower back lordosis is exacerbated, and the pelvis is inclined forward. In the swayback posture, the head protrudes forward, and the cervical spine is slightly extended. The upper trunk is depressed, and the thoracic flexion is accentuated (long kyphosis). The lower back is flattened and the, pelvis is inclined backward. ${ }^{22}$

Results were stored in duplicity in a database of the SPSS software (SPSS Inc., Chicago, IL, USA,
Release 16.0.2, 2008), and consistency and range were automatically checked. SPSS was used for statistical analyses. The Kolmogorov-Smirnov test was used to check the normal distribution of variables; continuous variables were described as means and standard deviations, and categorical variables, as absolute and relative frequencies. Possible associations between continuous variables were estimated using the Pearson linear correlation coefficients, and the Pearson chi-square test and the Fisher exact test were used to test the association between the variables under study and the homogeneity between proportions.

The Student $t$ test for independent samples and oneway analysis of variance (ANOVA) followed by the Tukey test were used to compare the measures of central tendency of the different groups. All analysis were two-tailed, and $\mathrm{p}$ values were calculated; the values of confidence interval, when calculated, were exact, and the level of significance was set at $5 \%$.

\section{Results}

During data collection, 2,600 puerperal women were seen in the healthcare unit. About $40 \%$ of them ( $n=$ 1,043 ) were excluded because they were younger than 18 years. All the others ( $n=1,557$ ) were contacted and invited to participate in the study. The participants in the pilot study were also included in the group of 312 participants that met eligibility criteria and were interviewed. Eighty puerperal women were selected using simple random sampling by drawing numbers. Mean ( \pm SD) women's age was $26.6( \pm 5.8)$ years, and 42 $(52.5 \%)$ were 20 to 29 years old.

In the whole sample, most deliveries were vaginal $(70.0 \%)$; for about half of the group of women, the interview was made at up to 30 days after delivery $(52.5 \%)$, and $95.0 \%(n=76)$ were breastfeeding. Almost all women reported doing housework (96.3\%) and holding up their babies regularly $(92.5 \%)$; most changed the baby's diapers (97.5\%) and often did it with the baby lying on a low surface. A little more than half $(52.5 \%)$ of the women had no paid job during gestation. In the group of women that worked $(47.5 \%)$, the most

Table 1 - Association between postpartum time, pain and PPD (Petrolina, Brazil, 2012), n (\%)

\begin{tabular}{lccc}
\hline Postpartum time & PWD with pain $(\mathbf{n}=\mathbf{5 4})$ & PD with pain $(\mathbf{n}=\mathbf{2 6})$ & Total \\
\hline Up to 30 & $14(29.8)$ & $5(10.6)$ & $47(58.8)$ \\
31 to 59 days & $1(20.0)$ & $2(40.0)$ & $5(6.3)$ \\
60 to 89 days & $1(14.3)$ & $2(28.6)$ & $7(8.7)$ \\
90 to 119 days & $1(14.3)$ & $0(0.0)$ & $7(8.7)$ \\
120 or more & $2(14.3)$ & $5(35.7)$ & $14(17.5)$ \\
Total & $19(23.8)$ & $14(17.5)$ & $80(100.0)$ \\
\hline
\end{tabular}

$\mathrm{PD}=$ puerperal women with depression; PPD = postpartum depression; PWD = puerperal women without depression.

* Pearson chi-square test.

34 - Trends Psychiatry Psychother. 2014;36(1) 
Table 2 - Association between pain site and PPD according to the NMQ before and during puerperium (Petrolina, Brazil, 2012), n (\%)

\begin{tabular}{|c|c|c|c|c|c|c|}
\hline \multirow[b]{2}{*}{ Pain site } & \multicolumn{2}{|c|}{$P D(n=26)$} & \multirow[b]{2}{*}{ p* } & \multicolumn{2}{|c|}{ PWD $(n=54)$} & \multirow[b]{2}{*}{ p* } \\
\hline & BP & $\mathbf{P}$ & & BP & $\mathbf{P}$ & \\
\hline Neck & $4(15.4)$ & $7(26.9)$ & 0.499 & $3(5.6)$ & $6(11.1)$ & 0.489 \\
\hline Shoulder & - & $3(11.5)$ & 0.235 & $3(5.6)$ & $5(9.3)$ & 0.716 \\
\hline Upper arm & - & $2(7.7)$ & 0.490 & $3(5.6)$ & $5(9.3)$ & 0.716 \\
\hline Elbow & $1(3.8)$ & - & 1.000 & $1(1.9)$ & - & 1.000 \\
\hline Lower arm & $1(3.8)$ & $1(3.8)$ & 1.000 & $2(3.7)$ & - & 0.495 \\
\hline Wrist, hand, fingers & $1(3.8)$ & $2(7.7)$ & 1.000 & $7(13.0)$ & $1(1.9)$ & 0.060 \\
\hline Lower back & $11(42.3)^{+}$ & $13(50.0)^{\ddagger}$ & 0.578 & $11(20.4)^{\dagger}$ & $12(22.2)^{\ddagger}$ & 0.814 \\
\hline Lower back & $14(53.8)$ & $9(34.6)$ & 0.163 & $20(37.0)$ & $17(31.5)$ & 0.543 \\
\hline Hip, lower extremities & $10(38.5)$ & $6(23.1)$ & 0.229 & $14(25.9)$ & $12(22.2)$ & 0.653 \\
\hline
\end{tabular}

$\mathrm{BP}=$ before puerperium; NMQ = Nordic Musculoskeletal Questionnaire; $\mathrm{P}=$ puerperium; $\mathrm{PD}=$ puerperal women with depression; PPD = postpartum depression; PWD = puerperal women without depression

* Pearson chi-square $\left(\chi^{2}\right)$ or Fisher exact test.

${ }^{+} \mathrm{p}=0.04$ between groups BP according to Pearson $\chi^{2}$ test.

$\neq \mathrm{p}=0.01$ between groups in $\mathrm{P}$ according to Pearson $\chi^{2}$ test.

Table 3 - Association between the position of body segments and PPD in anterior and posterior views, $\mathrm{n}(\%)$

\begin{tabular}{|c|c|c|c|c|}
\hline Segment & $P D(n=26)$ & PWD $(n=54)$ & Total & p* \\
\hline \multicolumn{5}{|l|}{ Anterior view } \\
\hline \multicolumn{5}{|l|}{ Head } \\
\hline Neutral & $18(69.2)$ & $38(70.4)$ & $56(70.0)$ & \multirow[b]{3}{*}{0.277} \\
\hline Tilt to the right & $4(15.4)$ & $13(24.1)$ & $17(21.3)$ & \\
\hline Tilt to the left & $4(15.4)$ & $3(5.6)$ & $7(8.8)$ & \\
\hline \multicolumn{5}{|l|}{ Pelvis } \\
\hline Neutral & $14(53.8)$ & $30(55.6)$ & $44(55.0)$ & \\
\hline Tilt to the right & $6(23.1)$ & $16(29.6)$ & $22(27.5)$ & \multirow[b]{2}{*}{0.616} \\
\hline Tilt to the left & $6(23.1)$ & $8(14.8)$ & $14(17.5)$ & \\
\hline \multicolumn{5}{|l|}{ Knees } \\
\hline Neutral & $12(46.2)$ & $23(42.6)$ & $35(43.8)$ & \multirow[b]{3}{*}{0.951} \\
\hline Vagus & $7(26.9)$ & $16(29.6)$ & $23(28.8)$ & \\
\hline Varus & $7(26.9)$ & $15(27.8)$ & $22(27.5)$ & \\
\hline \multicolumn{5}{|l|}{ Feet } \\
\hline Neutral & $5(19.2)$ & $18(33.3)$ & $23(28.8)$ & \multirow[b]{3}{*}{0.261} \\
\hline Vagus & $5(19.2)$ & $13(24.1)$ & $18(22.5)$ & \\
\hline Varus & $16(61.5)$ & $23(42.6)$ & $39(48.8)$ & \\
\hline \multicolumn{5}{|l|}{ Posterior view } \\
\hline \multicolumn{5}{|l|}{ Scapulae } \\
\hline Neutral & $3(11.5)$ & $8(14.8)$ & $11(13.8)$ & \multirow{5}{*}{0.025} \\
\hline Abducted & $12(46.2)$ & $38(70.4)$ & $50(62.5)$ & \\
\hline Adducted & $11(42.3)$ & $8(14.8)$ & $19(23.8)$ & \\
\hline Neutral & $8(30.8)$ & $19(35.2)$ & $27(33.8)$ & \\
\hline Depressed & $8(30.8)$ & 21 (38.9) & $29(36.3)$ & \\
\hline Elevated & $10(38.5)$ & $14(25.9)$ & $24(30.0)$ & \multirow[t]{3}{*}{0.512} \\
\hline Neutral & $9(34.6)$ & $23(42.6)$ & $32(40.0)$ & \\
\hline Winged & $9(34.6)$ & $20(37.0)$ & $29(36.3)$ & \\
\hline Rotated & $8(30.8)$ & $11(20.4)$ & $19(23.8)$ & 0.575 \\
\hline
\end{tabular}

$\mathrm{PD}=$ puerperal women with depression; PPD = postpartum depression; PWD = puerperal women without depression.

* Pearson chi-square test. 
Table 4 - Association between the position of body segments in the lateral view and PPD, $\mathrm{n}(\%)$

\begin{tabular}{|c|c|c|c|c|}
\hline Lateral view & PD $(n=26)$ & PWD $(n=54)$ & Total & p* \\
\hline \multicolumn{5}{|l|}{ Head } \\
\hline Forward & $26(100.0)$ & $54(100.0)$ & $80(100.0)$ & - \\
\hline \multicolumn{5}{|l|}{ Spine } \\
\hline Normal lordosis & $20(76.9)$ & $38(70.4)$ & $58(72.5)$ & \\
\hline Hyperlordosis & $5(19.2)$ & $14(25.9)$ & $19(23.8)$ & \\
\hline Flattened & $1(3.8)$ & $2(3.7)$ & $3(3.8)$ & 0.804 \\
\hline \multicolumn{5}{|l|}{ Right shoulder } \\
\hline Neutral & $1(3.8)$ & $2(3.7)$ & $3(3.8)$ & \\
\hline Forward & $25(96.2)$ & $52(96.3)$ & $77(96.3)$ & 1.000 \\
\hline \multicolumn{5}{|l|}{ Left shoulder } \\
\hline Neutral & $3(11.5)$ & $10(18.5)$ & $13(16.3)$ & \\
\hline Forward & $23(88.5)$ & $44(81.5)$ & $67(83.8)$ & 0.531 \\
\hline \multicolumn{5}{|l|}{ Thoracic spine } \\
\hline Normal kyphosis & $10(38.5)$ & $25(46.3)$ & $35(43.8)$ & \\
\hline Hyperkyphosis & $16(61.5)$ & $28(51.9)$ & $44(55.0)$ & \\
\hline Flattened & $0(0.0)$ & $1(1.9)$ & $1(1.3)$ & 0.598 \\
\hline \multicolumn{5}{|l|}{ Pelvis } \\
\hline Neutral & $11(42.3)$ & $16(29.6)$ & $27(33.8)$ & \\
\hline Hip anteversion & $11(42.3)$ & $28(51.9)$ & $39(48.8)$ & \\
\hline Hip retroversion & $4(15.4)$ & $10(18.5)$ & $14(17.5)$ & 0.532 \\
\hline \multicolumn{5}{|l|}{ Lower back spine } \\
\hline Normal lordosis & $11(42.3)$ & $15(27.8)$ & $26(32.5)$ & \\
\hline Hyperlordosis & $11(42.3)$ & $29(53.7)$ & $40(50.0)$ & \\
\hline Flattened & $4(15.4)$ & $10(18.5)$ & $14(17.5)$ & 0.429 \\
\hline \multicolumn{5}{|l|}{ Right knee } \\
\hline Extended & $25(69.4)$ & $28(51.9)$ & $53(58.9)$ & \\
\hline Hyperextended & $11(30.6)$ & $26(48.1)$ & $37(41.1)$ & 0.624 \\
\hline \multicolumn{5}{|l|}{ Left knee } \\
\hline Extended & $14(53.8)$ & $29(53.7)$ & $43(53.8)$ & \\
\hline Hyperextended & $12(46.2)$ & $25(46.3)$ & $37(46.3)$ & 0.990 \\
\hline
\end{tabular}

$\mathrm{PD}=$ puerperal women with depression; $\mathrm{PPD}=$ postpartum depression; $\mathrm{PWD}=$ puerperal women without depression.

* Pearson chi-square or Fisher exact test.

frequent occupation was housekeeping (17.5\%), followed by farming activities, and most (32.5\%) performed their activities while standing during all their working hours.

Of the 80 women that responded the EPDS, $32.5 \%$ ( $n$ $=26$ ) had a score that indicated PPD and were included in the depression group (puerperal women with depression - PD); the other women $(67.5 \% ; n=54)$ were included in the group without depression (puerperal women without depression - PWD). Of all puerperal women included in the study, $58.8 \%(n=47)$ reported mild or no pain: $72.2 \%(n=39)$ were in the PWD group, and $30.8 \%$ $(n=8)$, in the PD group $(p<0.001)$. The comparison of mean VAS scores revealed that pain was significantly more intense $(p=0.002)$ in the PD group $(6.3 \pm 2.5)$ than in the PWD group (4.4 \pm 2.5$)$.
There were no statistically significant associations between pain and delivery mode $(p=0.656)$, breastfeeding ( $p=0.608)$, housework and caring for the baby $(p=0.650)$, or work activities $(p=0.290)$. Similarly, postpartum time was not associated $(p=0.280)$ with the presence or absence of pain or PPD (Table 1 ).

The evaluation of pain in the 12 months before the interview (before puerperium, BP) revealed that the upper back was the site most often referred by women in the PD group (42.3 vs. $20.4 \% ; p=0.04$ ). Other very frequent pain sites were found in this group: neck, lower back, hip and lower extremities. However, findings were not statistically different from those found for the PWD group. During puerperium $(P)$, seven days before the interview, the prevalence of upper back pain was 
statistically greater $(p=0.01)$ in the PD group $(50.0 \%)$ than in the PWD group (22.2\%) (Table 2 ).

The analysis of posture frequencies revealed characteristics that were common to the puerperal women in this sample. In the anterior view, there was a prevalence of neutral postures of the head $(70 \%)$, pelvis $(55.0 \%)$ and knees (43.8\%), as well as a prevalence of varus foot alignment (Table 3 ). The prevalent posture was similar in both groups, and only scapular posture was significantly different ( $p<0.05)$, as there was greater prevalence of scapular abduction in the posterior view in the PWD group. The frequency of scapular postures in the PD group were greater for abduction (46.2\%) and elevation $(38.5 \%)$, and the percentages of the other types of posture were similar. In the PWD group, values were greater for abduction (70.4\%) and depression (38.9\%).

The most prevalent findings in lateral view were forward head (100.0\%), shoulder protrusion (96.3\% right shoulder; $83.8 \%$ left shoulder), thoracic hyperkyphosis (55.0\%) and hip anteversion (48.8\%) (Table 4). Hip anteversion was found in $51.9 \%$ of the puerperal women in the PWD group, differently from what was found in the PD group, in which the percentages of neutral position and anteversion were identical (42.3\%). The predominant lower back posture in the PWD group was hyperlordotic, found in $53.7 \%$ of the women; in the PD group, the rates of normal lordosis and hyperlordosis were identical, as were the rates found in the analysis of pelvic posture.

The evaluation of posture type in the PD group revealed that the most frequent pattern was kypholordotic (50.0\%; 95\% confidence interval [95\%CI] 29.9-70.1), whereas in the PWD group, it was the swayback pattern (48.2\%; 95\%CI 34.4-62.2). However, there was no statistically significant association between PPD and posture type ( $p=0.328$ ). In contrast, the comparison between mean VAS score and posture type revealed significantly more intense pain in the PD group when the posture type was swayback ( $p<0.001$ ). The intragroup analysis of variance did not reveal any statistically significant difference between posture types in PD ( $p=$ $0.316)$ or PWD ( $p=0.456)$ (Table 5).

\section{Discussion}

This study found higher VAS scores in the group of puerperal women with depression. Although our results do not show a linear association between EPDS and VAS scores, the pain reported by the participants was statistically associated with PPD.

A prospective longitudinal study conducted in France also found higher VAS scores among puerperal women at risk of PPD. However, differently from the results reported here, they found no statistical association between pain and a diagnosis of PPD at 8 weeks postpartum. Those authors concluded that physical pain might lead to false positive results when screening for PPD. ${ }^{23}$

The identification of depression may be difficult when the patients have physical complaints. ${ }^{24}$ Although a unidirectional causal relation is difficult to establish, an association has been found between depression and pain in musculoskeletal structures. ${ }^{25} \mathrm{~A}$ prospective study conducted in Canada found that most $(81.7 \%)$ puerperal women in their study reported pain at one or more postpartum time points. At the time of the interview, conducted at a mean 7.3 months after delivery, $27.1 \%$ of those women still had pain. Among puerperal women that reported pain, PPD prevalence was $7.7 \%$.

Pain in the upper back during pregnancy has been associated with pain in the same region after delivery, at a prevalence of about $40 \% .{ }^{26}$ In a Brazilian study, the highest prevalence of discomfort was in the lower back $(54 \%)$, followed by the upper back (35\%) and cervical region $(11 \%)$ in the puerperal period. ${ }^{13}$ In the same study, women without depression had proportionally similar percentages. However, in the group of women with depression, the highest prevalence of pain was in the upper back, followed by pain in the lower back, cervical region, hip and lower extremities.

A cohort study found a high prevalence $(76.6 \%)$ of back pain in women in the third trimester of pregnancy; two years later, $21.1 \%$ of them still reported pain in the same site. ${ }^{4}$ Our study had similar findings in the analysis of pain in the upper back in the PD group. The statistically significant difference of pain in the upper back at the

Table 5 - Intragroup comparison of mean VAS scores according to posture type, mean \pm SD

\begin{tabular}{lccc}
\hline \multirow{2}{*}{ Posture type } & \multicolumn{2}{c}{ VAS score } & \multirow{2}{*}{ p* } \\
\cline { 2 - 3 } & PD $(\mathbf{n}=\mathbf{2 6}) *$ & PWD (n = 54) & N/A \\
Flat back $(n=5)$ & $4.00 \pm N / A$ & $5.75 \pm 3.30$ & 0.103 \\
Kypholordotic & $5.69 \pm 2.96$ & $4.00 \pm 2.45$ & 0.718 \\
Lordotic & $6.00 \pm 1.41$ & $5.25 \pm 2.66$ & $<0.001$ \\
Swayback & $7.40 \pm 1.65$ & $4.27 \pm 2.27$ & \\
\hline
\end{tabular}

$\mathrm{N} / \mathrm{A}=$ not available; $\mathrm{PD}=$ puerperal women with depression; PWD = puerperal women without depression; SD = standard deviation; VAS = visual analog scale. $* p=0.316$, according to one-way ANOVA.

${ }^{+} \mathrm{p}=0.456$, according to one-way ANOVA.

₹ $t$ test for independent samples. 
two time points (pre-puerperium and puerperium) may suggest that pain in this region may be a predictive factor of PPD, as well as a comorbidity. Upper back pain is often associated with breast enlargement, poor maternal posture during breastfeeding, or the activities to care for the baby. ${ }^{27}$ Our study, however, did not confirm these findings, which may indicate that, in our sample, upper back pain might have been associated with PPD and not affected by any other risk factor.

Overall, puerperal women evaluated in this study had a similar posture. Therefore, we expected similar postural findings in both groups; however, hip anteversion and lordosis were predominant among women without depression, whereas the group with depression did not have the same postural characteristics. In this group, percentages were identical for neutral pelvic position and hip anteversion, as well as for normal lordosis and lower back hyperlordosis. Similarly, scapular postures were different in elevation or depression, and elevation was predominant in the group with depression, whereas depressed scapulae were more frequent in the group without depression. These findings may suggest that individuals have different postural responses to increased body mass, ${ }^{28}$ or that the presence of depressive symptoms may somehow affect body responses in puerperal women.

A study of posture analysis and body image in patients with acute major depression found a significant increase in forward head position and thoracic kyphosis, a tendency to thoracic kyphosis and an increase in interscapular distance, which characterizes a "depressive posture". ${ }^{18}$ This type of posture is similar to the swayback posture in increase of thoracic kyphosis and hip retroversion, and different in terms of head posture, which is placed forward, and spine, which is slightly extended. In our study, however, this posture type, not directly associated with PPD, was associated with pain intensity, greater in the PD group.

There is no ideal postural structure for human beings. The major concern of any individual should be in how to use their own body to perform its functions. In this sense, the analysis of anatomic and emotional aspects of posture should avoid definitions of what is normal or ideal. ${ }^{29}$

One of the limitations of this study was the use of a self-rating scale to determine PPD. Although EPDS is useful to screen women that may have depression, it has not been developed for PPD diagnosis, which is usually made by psychiatrists using semi-structured clinical interviews. ${ }^{11,19}$ However, EPDS is a recognized ${ }^{5,7}$ screening tool that may be used in daily clinical practice by multidisciplinary teams that work with women's mental health because of its low cost and the fact that it may be applied by any healthcare worker. Moreover, the highest cut-off point previously established by the author that developed the scale was used in this study to reduce the number of false positive results.

Another limitation was the fact that, although the number of women evaluated was greater than what was estimated in the calculation, sample size was small. Moreover, the use of a cross-sectional design limited the evaluation of posture before pregnancy-puerperium. Therefore, further longitudinal studies should investigate these issues.

\section{Conclusion}

This study found a strong association between pain intensity and PPD. In the group of puerperal women with depression, upper back pain seemed to be both a risk factor and a comorbidity of postpartum depression. The swayback posture, linked to depressive attitudes, was not positively associated with postpartum depression. However, our findings suggest that pain intensity and swayback posture are interdependent. Therefore, our results suggest that the association between depression and posture may occur indirectly by means of the painful event.

\section{References}

1. Horak FB, MacPherson JM. Postural orientation and equilibrium. In: Rowell LB, Sherpherd JT, editors. Handbook of physiology: a critical, comprehensive presentation of physiological knowledge and concepts. New York: Oxford American Physiological Society; 1996. p. 255-92.

2. Ostgaard HC, Andersson GB. Postpartum low-back pain. Spine (Phila Pa 1976). 1992;17:53-5.

3. Borg-Stein J, Dugan SA. Musculoskeletal disorders of pregnancy, delivery and postpartum. Phys Med Rehabil Clin N Am. 2007; 18:459-76.

4. To WW, Wong MW. Factors associated with back pain symptoms in pregnancy and the persistence of pain 2 years after pregnancy. Acta Obstet Gynecol Scand. 2003;82:1086-91.

5. Gaudet $C$. The association of acute and chronic postpartum pain with postpartum depression in a nationally representative sample of Canadian women [dissertation]. Ottawa: University of Ottawa; 2011.

6. Webb DA, Bloch JR, Coyne JC, Chung EK, Bennett IM, Culhane JF. Postpartum physical symptoms in new mothers: their relationship to functional limitations and emotional well-being. Birth. 2008;35:179-87.

7. Gutke A, Josefsson A, Oberg B. Pelvic girdle pain and lumbar pain in relation to postpartum depressive symptoms. Spine (Phila Pa 1976). 2007;32:1430-6.

8. McGovern P, Dowd B, Gjerdingen D, Gross CR, Kenney S, Ukestad $L$, et al. Postpartum health of employed mothers 5 weeks after childbirth. Ann Fam Med. 2006;4:159-67.

9. Cooper PJ, Tomlinson M, Swartz L, Woolgar M, Murray L, Molteno C. Post-partum depression and the mother-infant relationship in a South African peri-urban settlement. $\mathrm{Br}$ J Psychiatry. 1999;175:554-8.

10. Moraes IG, Pinheiro RT, Silva RA, Horta BL, Sousa PL, Faria AD. [Prevalence of postpartum depression and associated factors]. Rev Saude Publica. 2006;40:65-70.

11. Cantilino A, Zambaldi CF, Albuquerque TLC, Paes JA, Montenegro $A C P$, Sougey EB. Postpartum depression in Recife - Brazil: prevalence and association with bio-socio-demographic factors. J Bras Psiquiatr. 2010;59:1-9. 
12. Pawar G, Wetzker C, Gjerdingen D. Prevalence of depressive symptoms in the immediate postpartum period. J Am Board Fam Med. 2011;24:258-61.

13. Morari-Cassol EG. Amamentação e desconforto músculoesquelético da mulher [tese]. Brasília: Universidade do Estado de Brasília; 2007.

14. Abou-Saleh MT, Ghubash R. The prevalence of early postpartum psychiatric morbidity in Dubai: a transcultural perspective. Acta Psychiatr Scand. 1997;95:428-32.

15. Lowen A. O corpo em depressão: as bases biológicas da fé e da realidade. $4^{a}$ ed. São Paulo: Summus; 1983.

16. Teixeira MJ. Dor: contexto interdisciplinar. Curitiba: Maio; 2003.

17. Simon GE, VonKorff M, Piccinelli M, Fullerton C, Ormel J. An international study of the relation between somatic symptoms and depression. N Engl J Med. 1999;341:1329-35.

18. Canales JZ, Cordás TA, Fiquer JT, Cavalcante AF, Moreno RA. Posture and body image in individuals with major depressive disorder: a controlled study. Rev Bras Psiquiatr. 2010;32:375-80.

19. Cox JL, Holden JM, Sagovsky R. Detection of postnatal depression. Development of the 10-item Edinburgh Postnatal Depression Scale. Br J Psychiatry. 1987;150:782-6

20. Kuorinka $I$, Jonsson $B$, Kilbom A, Vinterberg $H$, Biering-Sørensen F, Andersson G, et al. Standardised Nordic questionnaires for the analysis of musculoskeletal symptoms. Appl Ergon. 1987;18:2337.

21. Huskisson EC. Measurement of pain. Lancet. 1974;2:1127-31.

22. Kendall FP, McCreary EK, Provance PG, Rod MM. Músculos: provas e funções. $5^{a}$ ed. São Paulo: Manole; 2007.
23. Jardri R, Maron $M$, Delion $P$, Thomas $P$. Pain as a confounding factor in postnatal depression screening. J Psychosom Obstet Gynaecol. 2010;31:252-5.

24. Kirmayer LJ, Robbins JM, Dworkind M, Yaffe MJ. Somatization and the recognition of depression and anxiety in primary care. Am J Psychiatry. 1993;150:734-41.

25 Rajala U, Keinänen-Kiukaanniemi S, Uusimäki A, Kivelä SL. Musculoskeletal pains and depression in a middle-aged Finnish population. Pain. 1995;61:451-7.

26. Breen TW, Ransil BJ, Groves PA, Oriol NE. Factors associated with back pain after childbirth. Anesthesiology. 1994;81:29-34.

27. Morari-Cassol EG, Campos Júnior D, Haeffner LSB. Musculoskeletal discomfort post-partum and breastfeeding. Fisioter Bras. 2008;9:9-16.

28. Gilleard WL, Crosbie J, Smith R. Static trunk posture in sitting and standing during pregnancy and early postpartum. Arch Phys Med Rehabil. 2002;83:1739-44.

29. Keleman S. Anatomia emocional. $5^{a}$ ed. São Paulo: Summus; 1992.

\section{Correspondence:}

Rita di Cássia de Oliveira Angelo

Rua Marcos Passos, 465, Vila Eduardo

56328-030 - Petrolina, PE - Brazil

Tel./Fax: +55 (87) 3031.6674/3866.9694/8851.9850

E-mail: ritangel@gmail.com 